\title{
Enteropatia ambiental
}

\author{
MAURO BATISTA DE MORAIS \\ e U LISSES FA GUNDES NETO
}

\section{Introdução}

$\mathrm{N}$ o FINAL DA DÉCADA de 1950, Margareth Shiner descreveu um método para a obtenção de fragmentos do intestino delgado para avaliação histológica. Pode-se dizer que esta descoberta da M edicina propiciou condições para o início de vários estudos que, após quase 25 anos, permitiram definir de maneira consistente a enteropatia ambiental. Esta condição clínica deve ser entendida como uma doença da sociedade, que acomete a saúde e a qualidade de vida de inúmeras pessoas, crianças e adultos que vivem em condições ambientais aquém da dignidade merecida por todos os componentes de uma sociedade civilizada (Fagundes N eto, 1996).

D urante a década de 1960, estudos realizados em países tropicais mostraram que indivíduos adultos sem manifestações clínicas gastrintestinais apresentavam alterações histológicas no intestino delgado e redução da capacidade de absorção da D -xilose, ao serem comparados com indivíduos adultos sadios moradores em países desenvolvidos. 0 primeiro destes estudos foi realizado por Sprinz e cols. (1962), na Tailândia, mostrando que os indivíduos adultos estudados, apesar de apresentarem anormalidades na mucosa intestinal, não apresentavam sintomatologia alguma. Klipstein, em 1970, compilou vários estudos realizados na Í ndia, Paquistão, M alaia, N igéria, E gito, I srael, V ietnan, H aiti, M éxico e Venezuela. No que se refere à morfologia, as anormalidades observadas no intestino delgado em todos estes estudos eram redução da altura das vilosidades intestinais e aumento do infiltrado linfoplasmocitário na lâmina própria.

I nicialmente, estas anormalidades receberam várias denominações, dentre as quais enteropatia tropical, má absorção subclínica dos países em desenvolvimento, enteropatia não específica e jejunopatia tropical. A similaridade destas lesões intestinais com o sprue tropical levaram Klipstein (1970), em 1967, a propor uma teoria baseada no clássico modelo do "iceberg", considerando que o grande contingente de indivíduos assintomáticos com anormalidades funcionais e morfológicas no intestino delgado constituiriam a porção submersa do sprue tropical subclínico. Por outro lado, a porção emersa do "iceberg" corresponderia ao sprue tropical clássico com suas manifestações clínicas características: diarréia crônica, emagrecimento e anemia megaloblástica por deficiência de vitamina B12 ou ácido fólico. Entretanto, uma série de argumentos fundamentados na distribuição geográfica, na predileção por certas faixas etárias e a possibilidade de o sprue tropical eclodir mesmo após o viajante retornar para uma região desenvol- 
vida, fizeram com que o próprio Klipstein (1979) reconsiderasse sua opinião, doze anos depois. N esta ocasião, afirmou que o spruetropical e a então enteropatia ambiental eram entidades clínicas distintas mas que poderiam coexistir em uma mesma região geográfica e até no mesmo indivíduo. Vale ressaltar que no Brasil não existe relato de sprue tropical.

0 reconhecimento inicial destas anormalidades intestinais no Brasil, deuse por um caminho diverso, uma vez que Fagundes N eto e cols. (1981) avaliaram um grupo de crianças sintomáticas, portadoras de diarréia crônica associada à desnutrição energético-protéica. $\mathrm{N}$ esta oportunidade, a enteropatia ambiental foi definida como uma síndrome cuja intensidade pode ser variável, de leve a grave, afetando crianças provenientes de famílias com baixo nível socioeconômico vivendo em situação de promiscuidade, com elevada taxa de contaminação ambiental, ausência de saneamento básico, ingestão alimentar deficiente, desmame precoce e que apresentam surtos diarréicos de repetição ou diarréia crônica. E m 1983, na literatura nacional, e em 1984 em revista européia, Fagundes $N$ eto e cols. propuseram a denominação enteropatia ambiental em substituição à enteropatia tropical. Ainda em 1984, o mesmo grupo propôs definir enteropatia ambiental como um conjunto de alterações inespecíficas do intestino delgado, funcionais e morfológicas, com ou sem exteriorização clínica reversíveis espontaneamente com a mudança para um ambiente com boas condições de salubridade (M orais, 1984).

A partir da segunda metade da década de 1990, a possibilidade de pesquisar sobrecrescimento bacteriano no intestino delgado, uma das características da enteropatia ambiental, com o teste do hidrogênio no ar expirado, possibilitou a realização de novos estudos na comunidade utilizando este método diagnóstico não invasivo.

\section{E tiopatogenia}

\section{Exposição a ambi ente com con di ções de salubri dade i nadequada}

D e início, pela diversidade étnica dos países onde se descreveu a entero patia ambiental em relação ao mundo desenvolvido, chegou-se a mencionar a possibilidade de que as anormalidades intestinais poderiam ser determinadas geneticamente. Poder-se-ia, assim, justificar a insensibilidade dos ricos frente à impossibilidade de contrariar o código genético dos pobres, ou seja, nada poderia ser feito para combater a enteropatia ambiental. No entanto, o imprescindível contato com ambiente inadequado ficou bem demonstrado em estudos realizados com soldados em ação nos países onde existia a enteropatia ambiental. Estes soldados apresentavam as anormalidades funcionais e morfológicas da enteropatia ambiental que também podiam ocasionar manifestações clínicas. Funcionários das embaixadas destes países também apresentavam as mesmas anormalidades intestinais, porém em grau menos intenso do que os solados que viviam em contato mais íntimo com o ambiente (Fagundes N eto, 1996 e M orais, 1984). 
O bservou-se também que a enteropatia ambiental não ocorre no período neonatal, de modo que ela, ao contrário da desnutrição energético-protéica, não pode ter início na vida intra-uterina. Por outro lado, demonstrou-se, no Paquistão, que a redução de absorção da D -xilose pela enteropatia ambiental era melhor evidenciada após os seis meses de idade. É provável que isto ocorra não especificamente em função da idade, mas sim de forma concomitante com a interrupção do aleitamento natural exclusivo durante o processo de desmame (Fagundes $\mathrm{N}$ eto, 1996 e M orais, 1984).

Em nosso país, a maior parte dos estudos sobre enteropatia ambiental foram realizados com crianças moradoras em favelas, que constitui ambiente francamente favorável ao seu aparecimento.

A possibilidade de reversão espontânea do déficit de absorção da D-xilose após a mudança de ambiente com condições adequadas de salubridade constitui uma característica importante da enteropatia ambiental por demonstrar que é possível sua erradicação melhorando as condições ambientais. Este aspecto foi demonstrado por Gerson e cols., avaliando indianos e paquistaneses que mudaram para N ova I orque ${ }^{10}$. Estes indivíduos eram avaliados assim que chegavam em N ova I orque e após al guns meses morando naquela cidade sem receber nenhum tipo de tratamento específico. O bservou-se que praticamente todos os indivíduos estudados apresentaram aumento da absorção da D -xilose (Gerson et al., 1971).

\section{A ção bacteriana na morfologia e fisi ologia do intesti no del gado}

L evando-se em consideração o paralelismo existente entre a taxa anual de episódios de diarréia e a intensidade da má absorção da $D$-xilose verificados no sul da Í ndia, Baker (1976) relacionou a participação de agentes enteropatogênicos na gênese da enteropatia ambiental, afirmando que os episódios repetidos de infecção intestinal poderiam provocar uma lesão duradoura do intestino delgado. Klipstein, em 1979, também partilhou desta proposta afirmando que as evidências disponíveis naquela época apontavam que a enteropatia ambiental constituía uma lesão residual dos repetidos episódios de colonização intestinal por diferentes entero patógenos. U m argumento adicional para esta hipótese é a presença de bactérias enteropatogênicas nas fezes de grande proporção de crianças assintomáticas, conforme demonstrado em estudos realizados em favela da cidade de São Paulo e em estudos sobre diarréia aguda onde os grupos controles constituídos por crianças sem diarréia também apresentam al tas taxas de bactérias enteropatogênicas (Fagundes $\mathrm{N}$ eto et al., 1995).

Em parcela considerável dos portadores de enteropatia ambiental observase a presença de sobrecrescimento bacteriano no intestino delgado. Sobrecrescimento bacteriano caracteriza-se pela colonização do intestino delgado por bactérias que normalmente são encontradas apenas na microbiota colônica (Fagundes $\mathrm{N}$ eto, 1996). As primeiras descrições de sobrecrescimento bacteriano no intesti- 
no delgado foram realizadas em pacientes com anormalidades anatômicas ou cirúrgicas. Posteriormente, passou a ser reconhecido em crianças que não apresentavam anormalidades anatômicas, em situações como desnutrição energéticoprotéica, diarréia aguda, diarréia persistente e enteropatia ambiental. 0 sobrecrescimento bacteriano pode determinar má absorção intestinal assintomática ou manifestar-se com diarréia crônica associada à desnutrição energético-protéica e déficit de crescimento. $\mathrm{N}$ a vigência do sobrescimento bacteriano no intestino delgado observam-se alterações funcionais e/ ou morfológicas decorrentes da capacidade de estas bactérias promoverem a desconjugação de sais biliares, assim como 7-a-desidroxiliação dos mesmos, transformando-os em sais biliares secundários. A desconjugação dos sais biliares acarreta diminuição na capacidade de formação da micela mista no processo de digestão e absorção de lipídeos, em virtude de sua concentração no lúmen intestinal não atingir a concentração micelar crítica. Portanto, observa-se menor solubilização das gorduras da dieta ocasionando esteatorréia. Por outro lado, os ácidos biliares secundários (deoxicólico e litocólico) apresentam grande capacidade de provocar lesões na mucosa intestinal acarretando atrofia vilositária parcial que pode associar-se com secreção de água e eletrólitos e má absorção de glicose (F agundes N eto, 1996).

O sobrecrescimento bacteriano pode interferir também na digestão e abso rção de carboidratos por vários mecanismos: 1. M etabolização dos carboidratos pelas próprias bactérias do sobrecrescimento bacteriano, gerando a formação de ácidos graxos de cadeia curta (acético, propiônico e butírico) e gases como o hidrogênio que, após difusão através da mucosa intestinal, alcança os pulmões por meio da circulação, sendo eliminado no ar expirado; 2. Diminuição da atividade das dissacaridases devido às alterações na ultraestrutura do intestino delgado (Fagundes N eto, 1996).

D esta forma, os carboidratos não absorvidos permanecem na luz intestinal na sua forma original ou na forma de ácidos graxos de cadeia curta resultantes da fermentação bacteriana, gerando força osmótica que promove secreção de água para a luz intestinal (Fagundes $N$ eto, 1996).

Existem evidências também de diminuição da absorção de proteínas da dieta por catabolismo protéico intraluminal e redução da digestão proteíca e do transporte e captação dos aminoácidos pela mucosa intestinal (Fagundes N eto, 1996).

D o ponto de vista fisiopatológico, o sobrecrescimento bacteriano do intestino delgado é resultado de um distúrbio na homeostase da flora bacteriana do intestino delgado conseqüente a desequilíbrio dos seus mecanismos de controle. De uma maneira geral, aceita-se que o trato digestivo superior (estômago, duodeno, jejuno) é estéril, o que ocorre em $70 \%$ dos indivíduos, ou pode apresentar uma escassa microflora constituída por microorganismos facultativos, predominantemente bactérias gram-positivas. A concentração de bactérias (estreptococos, lactobacilos, aeróbios e difterióides) e fungos normalmente não ultrapassa 
$10^{4}$ colônias/ $\mathrm{ml}$ do fluido obtido na luz do tubo digestivo. Estes microrganismos são provenientes da cavidade oral, colonizando o intestino delgado superior após sobreviver à acidez gástrica. A porção terminal do íleo constitui uma zona de transição e a microbiota começa a se modificar com o aparecimento de bactérias gram-negativas, como os coliformes e bacterióides. A válvula íleo-cecal atua como uma verdadeira barreira, separando as espécies gram-positivas predominantes no intestino delgado superior das espécies gram-negativas que habitam 0 cólon, onde a população de bactérias anaeróbias representa o principal contigente da microflora colônica. Bacteróides, lactobacilos anaeróbios e C lostridium sp são os principais componentes da flora colônica em concentrações que varia entre $10^{8}$ e $10^{11}$ colônias/ $\mathrm{mL}$, sobrepujando a microflora facultativa ou aeróbica em uma proporção de 1.000 a 10.000:1 (Fagundes N eto, 1996).

A manutenção da microbiota intestinal com as características mencionadas acima depende da ação de vários mecanismos reguladores, entre os quais o tipo de alimentação, motilidade do tubo digestivo, acidez gástrica, sistema imunológico intestinal e válvula íleo-cecal.

Tipo de alimentação - Animais criados em condição ambiental estéril, incluindo a ração, possuem características que o diferenciam dos animais criados em condições normais e que apresentam colonização do tubo digestivo. O s animais livres de bactérias apresentam o ceco dilatado, o tecido linfático hipodesenvolvido e níveis reduzidos de imunoglobulinas no soro. A parede intestinal destes animais é mais fina, não se observando o infiltrado linfo-plasmocitário na lâmina própria que é observado nos animais criados em ambiente normal e que apresentam colonização do tubo digestivo. N o ser humano, durante a gestação, o intestino do feto é estéril. Logo após o parto, o intestino do recém-nascido é colonizado rapidamente por bactérias provenientes do canal vaginal materno e do meio ambiente. Entretanto, a flora bacteriana depende também do tipo de leite utilizado na al imentação. $\mathrm{N}$ as crianças que recebem aleitamento natural predominam os lactobacilos bífidos que representam entre $95 \%$ e $99 \%$ das bactérias da luz intestinal. Q uando o lactente é al imentado com fórmulas lácteas, além das bifidobactérias aparecem bacterióides e anaeróbios (Fagundes N eto, 1996).

$\mathrm{N}$ este sentido, vale lembrar que animais coprofágicos apresentam maior número de bactérias no intestino delgado proximal em relação aos humanos, mas no cólon o número de bactérias é semelhante (Lichtman, 2000). Em situações ambientais inadequadas, especialmente quando as condições climáticas são favoráveis, os humanos podem ingerir alimentos com maior quantidade de bactérias que poderão vencer as barreiras antibacterianas do tubo digestivo ( $L$ ichtman, 2000).

Secreção ácida gástrica - É considerado como um dos fatores mais importantes para a regulação da microflora do intestino delgado por destruir grande parte das bactérias provenientes da cavidade oral ou ingeridas com os alimen- 
tos. Em pacientes com hipo ou acloridria secundária a gastrectomia ou ao uso de medicamentos antiácidos, pode ser observado aumento no número de bactérias no intestino delgado proximal. No intestino delgado, as secreções digestivas, pancreática e biliar, também colaboram no controle da microbiota intestinal.

M otilidade do tubo digestivo - O s movimentos peristálticos propulsivos no sentido crânio-caudal exercem um importante papel na manutenção da microbiota intestinal (Fagundes $\mathrm{N}$ eto, 1996 e Lichtman, 2000).

I munidade da mucosa intestinal - As respostas imunes na mucosa intestinal são diferentes daquelas que ocorrem sistemicamente. U ma das diferenças fundamentais é a produção da imunoglobulina A (IgA) secretora no intestino. Esta é a principal classe de anticorpos produzidas no intestino, o que pode ser exemplificado pelo maior número de células produtoras de IgA na proporção de vinte para cada célula produtora de IgG e três de IgM , conforme demonstrado em estudos de imunofluorescência. A I gA secretora se diferencia, também, da I gA sérica por encontrar-se na forma de dímeros, formados pela peça secretora, que também confere resistência para I gA contra a proteólise na luz intestinal. A IgA secretora tem a capacidade de impedir a aderência de microrganismos à superfície dos enterócitos, o que constituiu um importante mecanismo de controle do SBBO. É importante ressaltar que o recém-nascido possui pequena população de plasmócitos na lâmina própria do intestino, o que explica sua menor capacidade de resposta aos estímulos antigênicos locais. N esta fase da vida, o colostro e o leite materno, que são ricos em IgA secretora, desempenham importante papel na defesa do recém-nascido.

Válvula íleo-cecal - Atua como uma verdadeira barreira entre as bactérias gram-positivas habitantes do intestino delgado proximal e as bactérias gramnegativas e anaeróbias que constituem a flora bacteriana colônica. $\mathrm{N}$ a ausência da válvula íleo-cecal por ressecção intestinal observa-se a colonização retrógrada do intestino delgado com bactérias que normal mente são encontradas apenas no cólon (Lichtman, 2000).

Fundamentalmente, sobrecrescimento bacteriano do intestino delgado desenvolve-se quando ocorre alteração de um ou mais dos mecanismos reguladores da mucosa intestinal. Teoricamente, as bactérias do sobrecrescimento bacteriano podem ser provenientes tanto do ambiente, pela ingestão de alimentos e água contaminada, como da própria microbiota colônica, por distúrbios da motilidade intestinal ou insuficiência funcional da válvulaíleo-cecal. Assim, na enteropatia ambiental, o desenvolvimento do sobrescimento bacteriano é conseqüência de aumento da carga bacteriana ingerida, mas também podem ocorrer outras anormalidades na regulação da flora entérica, como redução da secreção ácida gástrica e na imunologia da mucosa, especialmente quando a criança já apresenta desnutrição energético-protéica. 


\section{D eficiência denutrientes}

$\mathrm{N}$ a desnutrição energético-protéica grave podem ser evidenciadas atrofia das vilosidades intestinais, tanto no marasmo quanto no kwashiokor. Deve ser enfatizado que no kwashiokor pode ser encontrada atrofia vilositária total. D esta forma, um processo que se iniciou com ingestão alimentar insuficiente pode, durante a evolução, associar-se com má absorção em função do comprometimento enteral que pode contribuir para o agravo progressivo do estado nutricional (Fagundes-N eto, 1996). Se esta questão for analisada criticamente, pode-se dizer que será muito difícil discernir o quanto estas lesões intestinais são dependentes da enteropatia nutricional ou da enteropatia ambiental. Este aspecto pode ser estendido para as parasitoses intestinais. I sto ocorre porque a desnutrição, as parasitoses intestinais e a enteropatia ambiental têm marcante predileção pelo segmento menos privilegiado da população mundial, refletindo diferentes facetas de uma mesma situação de miséria.

N a década de 1960, observou-se que crianças com anemia ferropriva apresentavam redução da absorção da D -xilose e atrofia parcial das vilosidades intestinais reversíveis com o tratamento da anemia por meio da ferroterapia ( $G$ uba et al., 1968). Por sua vez, crianças com anemia ferropriva apresentam aumento do peso e estatura durante a ferroterapia (M orais et al., 1993). Assim, é possível especular que possa existir uma relação entre a deficiência de ferro e a enteropatia ambiental. N este sentido, estudo recentemente real izado na G uatemala mostrou associação entre anormalidade da permeabilidade intestinal a lactulose e manitol, como indicação de enteropatia ambiental e evidência de deficiência de ferro ( $G$ oto et al., 1999). A relação entre deficiência de ferro e anormalidades na morfologia intestinal foi avaliada em condições experimentais em nosso laboratório (Chang et al., 2000). O bservou-se que ratos com anemia ferropriva apresentam hipertrofia das vilosidades intestinais aferidas por morfometria do intestino delgado. N estes animais não se observou, também, redução da absorção da D-xilose (Chang et al., 2000). Esta resposta com aumento na dimensão das vilosidades intestinais permite descartar a participação da deficiência de ferro na gênese da enteropatia ambiental e, mais uma vez, constata-se que as mesmas entidades comprometem as mesmas crianças vivendo em situação desfavorecida.

\section{A presentação clínica}

A enteropatia ambiental pode ser encontrada em duas formas clínicas: assintomática e sintomática (Fagundes N eto, 1996 e M orais, 1984).

Em nossa instituição, a enteropatia ambiental foi reconhecida inicialmente na forma sintomática (Faundes $\mathrm{N}$ eto et al., 1981). A manifestação clínica predominante foi a diarréia crônica. A desnutrição energético-protéica e condições ambientais inapropriadas, caracterizada pela falta de saneamento básico, baixa renda e escolaridade dos pais estavam sempre presentes. D e 112 pacientes avaliados, cerca da metade foi em regime ambulatorial e a outra metade durante inter- 
nação hospitalar. Este segundo grupo, necessitando de terapia nutricional em função de intolerâncias alimentares e terapia de reidratação parenteral, apresentava maior risco de morte em função de complicações infecciosas. No que se refere à idade, são mais novos do que os acompanhados ambulatorialmente. Caracterizouse nestes pacientes com enteropatia ambiental má absorção de lactose em 50\% dos casos, má absorção de sacarose em 30\% e de glicose em 5\%, mostrando que modificações dietéticas podem ser necessárias no tratamento da enteropatia ambiental.

Em um segundo momento, as investigações sobre enteropatia ambiental foram desenvolvidas na própria comunidade. 0 primeiro estudo sobre enteropatia ambiental assintomática foi realizado em uma comunidade da periferia da cidade de São Paulo, onde se observou redução na média da absorção da D -xilose em relação aos valores observados em países desenvolvidos (M orais et al., 1984). $N$ esta comunidade, naquele momento, observava-se também elevada prevalência de desnutrição energético-protéica (M orais et al., 1983). A partir de então, iniciou-se um programa de assistência e pesquisa destinada a uma comunidade de favelados (Fagundes N eto, 1996). O foco do programa voltava-se para a promoção das ações básicas de saúde, em particular, o incentivo ao al eitamento natural exclusivo. No que se refere à pesquisa clínica, constatou-se que lactentes desmamados e assintomáticos apresentavam redução da absorção da D -xilose, sobrecrescimento bacteriano e atrofia vilositária parcial na mucosa do intestino delgado configurando o quadro da enteropatia ambiental (Fagundes $\mathrm{N}$ eto et al., 1992). A análise da ultraestrutura intestinal por microscopia eletrônica revelou anormalidades em todos os espécimes examinados (Gusmão et al., 1993).

Conforme mencionado, a partir da década de 1990, foi possível realizar estudos utilizando o teste do hidrogênio no ar expirado para pesquisar a ocorrência de enteropatia ambiental, a partir da caracterização de sobrecrescimento bacteriano no intestino delgado. N este sentido, Pereira et al. (1991) estudaram 340 crianças com menos de cinco anos de idade e encontraram sobrecrescimento bacteriano no intestino delgado de $27,2 \%$ desta população, em uma vila da Austrália.

$\mathrm{N}$ o Brasil, foram realizados alguns estudosutilizando o teste do hidrogênio no ar expirado com a lactulose para caracterizar sobrecrescimento bacteriano associado à enteropatia ambiental. U m estudo envolvendo 83 escolares moradores na zona rural, zona urbana ou em favela de uma cidade no interior do Estado de São Paulo, sudeste do Brasil, revelou sobrecrescimento bacteriano em 7,2\% das crianças investigadas (Reis et al., 1999). N este estudo, a proporção de sobrecrescimento bacteriano nas crianças morados em favela (18,2\%) foi estatisticamente superior à das crianças que não moravam em favela, nas quais não se identificou sobrecrescimento bacteriano. Assim, o teste do hidrogênio no ar expirado demonstrou associação entre condição ambiental inadequada e sobrecrescimento bacteriano. O utro estudo (Alves et al., 2002) realizado em uma reserva indígena no $\mathrm{M}$ ato $\mathrm{G}$ rosso do Sul mostrou sobrecrescimento bacteriano em 11,5\% das 252 crianças estudadas. É possível que este valor seja subestimado, uma vez 
que, neste projeto foi utilizada dose de cinco gramas de lactulose em vez de dez gramas usada em outras publicações. R eis (2002) utilizando o teste do hidrogênio no ar expirado em cinqüenta crianças moradoras de uma favela, comparou com cinqüenta crianças controles, que viviam em moradias com boas condições ambientais e que pertenciam a famílias com bom nível socioeconômico. Sobrescimento bacteriano foi investigado com o após administração de lactulose (10 g) e, em outro dia, com glicose $(50 \mathrm{~g})$. A pós excluir as crianças não produtoras de hidrogênio, sobrecrescimento bacteriano foi observado em 50,0\% (23/46) das crianças moradoras em favela e em 2,2\% ( $1 / 46)$ das crianças controle. 0 teste do hidrogênio, após a ingestão de glicose, não permitiu caracterizar maior freqüência de SBBO nas crianças moradoras na favela. A Figura 1 mostra as curvas baseadas nas médias da concentração de hidrogênio no ar expirado, demonstrando que a produção de hidrogênio nas crianças moradoras em favela foi maior do que no grupo controle, indicando, indiretamente, maior quantidade de bactérias com capacidade de fermentar a lactulose no intestino das crianças moradoras na favela. A média ( \pm desvio-padrão) dos escores $Z$ de peso para a idade $(-0,45 \pm 0,95)$ e estatura para a idade $(-0,66 \pm 1,05)$ das crianças morados em favela foram inferiores ao grupo controle ( $+0,39 \pm 0,97$ e $+0,18 \pm 0,84$, respectivamente), sendo a diferença estatisticamente significante, e mostrando associação entre sobrecrescimento bacteriano e desnutrição energético-proteíca.

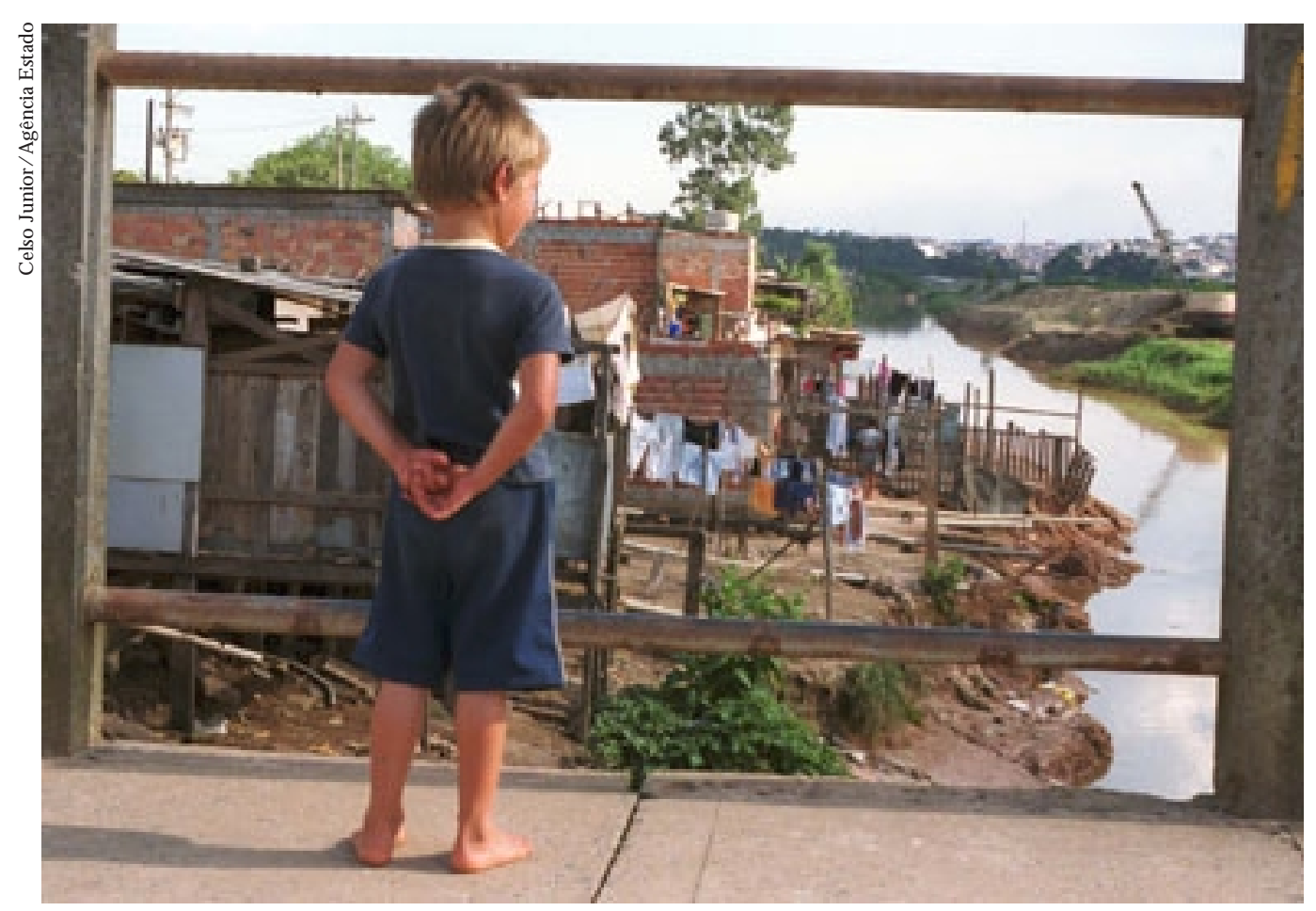

C riança observa enchente do rio Baquirivu, com favelasa sua margem, em Guarulhos, São Paulo.

As evidências apresentadas mostram que condições ambientais inadequadas, com falta de saneamento básico e de distribuição de água tratada, podem propi- 
ciar condições para consumo de água e alimentos contaminados que determinam não somente episódios de diarréia aguda, como também anormalidades perenes na função intestinal que podem comprometer a condição de saúde deste grande contingente da po pulação mundial acometida pela enteropatia ambiental.

Figura 1

M ediana da Concentração de $\mathrm{H}$ idrogênio no Ar Expirado por C rianças M oradoras em Favelas $(n=50)$ e Controles $(n=50)$ após a Ingestão de Lactulose (10 g) ou Glicose (50 g)

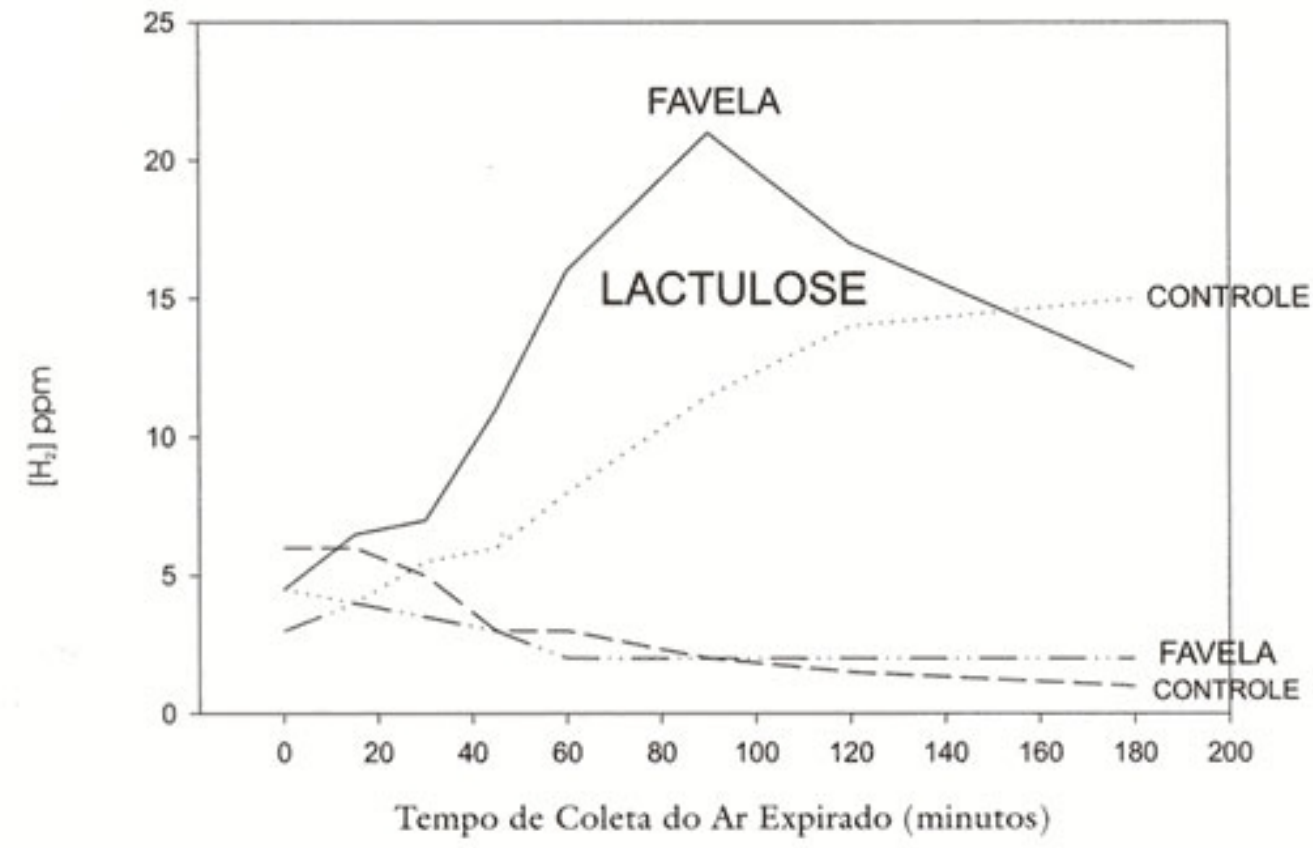

Para finalizar, é importante ressaltar que, com exceção da terapia de suporte destinada aos pacientes com manifestações de maior gravidade, o controle da enteropatia ambiental depende fundamental mente da melhoria das condições de vida da sociedade. A persistência da enteropatia ambiental é a conseqüência do fracasso das políticas sociais e de saúde pública.

\section{Bibliografia}

ALVES, G. M. S.; M ORAIS, M. B. e FAGU NDES-NETO, U. "Estado nutricional e teste do hidrogênio no ar expirado com lactose e lactulose em crianças indígenas terenas". J Pediatr, Rio de Janeiro, 78(2), 2002, pp. 113-119.

BAKER, S. J. "Subclinical Intestinal M alabsorption in D eveloping Countries". Bull World H ealth Organ, 54(5), 1976, pp. 485-494.

CHANG, M. L.; PATRÍCIO, F. S. R.; AMÂNCIO, O. M. S.; PEDROSO, M. Z.; FAGU NDES NETO, U . e M ORAIS, M. B. "I ron-deficiency Anemia I ncreases I ntestinal Villous H eight in Rats". J Pediatr Gastroenterol N utr, 31(2), 2000, p. S86. 
FAGU N DES-NETO, U .; SCH M ITZ, L. G. e SCALETSKY, I. “C aracterísticas clínicas e epidemiológicas da diarréia aguda por E scherichia Coli enteropatogênica clássica". R ev. A ssoc. M ed. Bras, 41(4), 1995, pp. 259-265.

FAGUNDESNETO, U .; MARTINS, M. C. V; LIMA, F. M. L. S; PATRÍCIO, F. R. S; M ACH AD O, N . L. e TO LED O, M. F. R. "Symptomatic Environmental Enteropathy in Infancy: Bacterial Proliferation, Funcional and M orphological Alterations of the Small Bowel". R ev. H osp. São Paulo Esc. Paul. M ed, 4(1/ 4), 1992, pp. 64-70.

FAGU N DESNETO, U . Enter opatia ambiental. Rio de Janeiro, Revinter, 1996, 203 p.

FAGU NDESNETO, U .; VIARO, T.; WEH BA, J.; MACH ADO, N . L.; PATRÍCIO, F. R. e M ICH ALANY, J. "E nteropatia tropical: alterações morfológicas e funcionais do intestino delgado e suas repercussões sobre o estado nutricional". A rq Gastroenterol, 18(4), 1981, pp. 177-182.

FAGU NDESNETO, U.; VIARO, T.; WEH BA, J.; PATRÍCIO, F. R. e M ACHADO, N. L. "Tropical Enteropathy (Environmental Enteropathy) in Early Childhood: A Syndrome Caused by Contaminated Environment". J Trop Pediatr, 30(4), 1984, pp. 204-209.

FAGUNDESNETO, U.; VIARO, T.; WEHBA, J.; PATRÍCIO, F. R. e MACHADO, N. L. "Enteropatia tropical: na infância: uma síndrome decorrente da contaminação ambiental (enteropatia ambiental)" . J Pediatr, R io de J aneiro, 54, 1883, pp. 313-319.

GERSON, C. D.; KENT, T. H.; SAHA, J. R.; SIDDIQI, N.e LINDENBAUM, J. "Recovery of Small-intestinal Structure and Function After Residence in the Tropics. II. Studies in Indians and Pakistanis Living in N ew York City". A nn Intern Med, 75(1), 1971, pp. 41-48.

GOTO, K.; CHEW, F.; TORÚ N , B.; PEERSON, J. M . eBROWN , K. H . “Epidemiology of Altered Intestinal Permeability to Lactulose and M annitol in Guatemalan Infants". J Pediatr Gastroenterol N utr, 1999, 28, pp. 282-290.

GUHA, D. K.; WALIA, B. N. S., TANDON, B. N., DEO, M. G. e GHAI, O. P. "Small Bowel Changes in I ron D eficiency Anaemia of Childhood". A rch Dis Childh, 1968, 43, pp. 239-244.

GU SM ÃO, R. H. P.; M ARTINS, M. C. V.; GU SM ÃO, S. R. B. eFAGU N DES NETO, $U$. "Enteropatia ambiental: estudo ultra-estrutural da mucosa jejunal de crianças assintomáticas/ Ambiental I ntestinal D iseases: U Itrastructure of the J ejunum M ucosa of Asymptomatic Children". J. Pediatr., Rio de J aneiro, 1993, 69(1), pp. 21-26.

KLIPSTEIN , F. A. "Recent Advances in Tropical M alabsorption". Scand J Gastroenterol Suppl, 6, 1970, pp. 93-114.

KLIPSTEIN , F. A. "Sprue and Subclinical M alabsorption in the Tropics" . Lancet, 1979, 1(8110), pp. 277-278.

KLIPSTEIN, F. A. "Tropical Sprue - An Iceberg Disease?" Ann Intern Med, 1967, 66(3), pp. 622-623.

LICHTM AN, S. N. "Bacterial O vergrowth". Allan Walker, D urie PR, H amilton JR,

MORAIS, M. B.; FAGUNDES NETO, U., GOMES, P. C. "Avaliação do estado nutricional de crianças moradoras em uma comunidade da periferia da cidade de São Paulo (J ardim Sabia)". J. Pediatr., Rio de J aneiro, 1983, 55(3), pp. 211-217. 
M ORAIS, M . B.; FERRARI, A. A.; M AU RO, F. "Effect of O ral I ron Therapy on Physical Growth". Rev Paul Med, 1993, 111(6), pp. 439-444.

M O RAIS, M. B. Capacidade de absorção da D-xilose em duas comunidades brasileiras crianças da periferia da cidade de São Paulo e criançasíndias do A Ito X ingu. D issertação de M estrado. Escola Paulista de M edicina, São Paulo, 1984.

M ORAIS, M. B.; FAGU N DESNETO, U . eMACH ADO, N . L. "Enteropatia ambiental em crianças moradoras na periferia da cidade de São Paulo". J . pediatr., Rio de J aneiro, 1984, 57(1), pp. 32-36.

PEREIRA, S. P.; KH IN-M Aung-U; BOLIN, T. D.; DU N COMBE, V. M .; NYUNTNYU NT-WAI; M YO-KH IN e LINKLATER, J. M. "A Pattern of Breath H ydrogen Excretion Suggesting Small Bowel Bacterial O vergrowth in Burmese Village C hildren". J Pediatr Gastroenterol N utr, 1991, 13(1), pp. 32-38.

REIS, J. C.; MORAIS, M. B. e FAGU NDES NETO, U. "Teste do H 2 no ar expirado na avaliação de absorção de lactose e sobrecrescimento bacteriano no intestino delgado de escolares". A rq. Gastroenterol, 1999, 36(4)pp. 169-176.

SPRINZ, H ., SRIBH IBH ADH , R., GANGAROSA, E. J .; BEN YAJATI, C.; KU NDEL, D. e H ALSTEAD, S. "Biopsy of Small Bowel of that People". A m J Clin Path, 1962, 38, pp. 43-51.

WALKER-SM ITH, J. A. e WATKIN S, J. B. Pediatric Gastrointestinal Disease. 3 ed., Decker, $\mathrm{H}$ amilton, 2000, pp. 569-582.

Mauro Batista de M orais é professor associado da disciplina de Gastroenterologia do D epartamento de Pediatria da U niversidade Federal de São Paulo/ Escola Paulista de M edicina.

U lyssesF agundes $N$ eto é professor titular da disciplina de G astroenterologia do D epartamento de Pediatria da U niversidade Federal de São Paulo/ E scola Paulista de M edicina.

Texto recebido e aceito para publicação em 2 de junho de 2003. 
